\title{
Overactive bladder: strategies to ensure treatment compliance and adherence
}

\author{
This article was published in the following Dove Press journal: \\ Clinical Interventions in Aging \\ 3 June 2016 \\ Number of times this article has been viewed
}

\section{Prabhpreet Dhaliwal Adrian Wagg}

Department of Medicine, University of Alberta, Edmonton, Canada
Correspondence: Adrian Wagg Department of Medicine, University of Alberta, I-108 Clinical Sciences Building, I I 350 - 83 Avenue, Edmonton, T6G 2P4, Canada

Tel +l 7804925338

Email adrian.wagg@ualberta.ca

\begin{abstract}
Overactive bladder is a common, debilitating condition for many patients who may benefit from pharmacological management of their condition. However, adherence to medication in this condition is markedly worse than other chronic medical conditions. This review explores what is known about persistence and the factors which influence medication adherence for overactive bladder, those factors that might be modifiable to improve adherence, and the measures the health care provider can take to optimize adherence to therapy and thereby improve treatment outcomes.
\end{abstract}

Keywords: overactive bladder, persistence, adherence

\section{Introduction}

Overactive bladder (OAB) is a clinically diagnosed chronic disorder characterized by urinary urgency, frequency, and nocturia with or without urgency incontinence, in the absence of other obvious urological pathology. ${ }^{1,2}$ Population studies in Europe, Canada, Korea, and the US have shown OAB symptoms to be present in $11.8 \%-16.5 \%$ of adults and to occur at a similar incidence in females and males in late life. Although $\mathrm{OAB}$ can cause problems for people of all ages, its prevalence increases in association with age. ${ }^{3}$ OAB will, on balance of probability, become more common as the number of people in the population surviving beyond their eighties increases. For example, in Canada, the proportion of people aged $\geq 65$ years rose from $8 \%$ to $14 \%$ between 1960 and 2009 , and this is likely to rise to $23 \%-25 \%$ by 2036 ; the population aged $\geq 80$ years will more than double between 2009 and $2036 .{ }^{4} \mathrm{~A}$ similar pattern is projected for the UK where by 2035 those aged $\geq 65$ years are likely to make up $23 \%$ of the population (compared with 17\% in 2010), with the greatest growth in those aged $\geq 85$ years $^{5}$ and is reflected across the majority of the other EU-27 countries; for example, Germany has a projected $31 \%$ of the population aged $\geq 65$ years by 2035.5 Several common chronic medical conditions, such as depression, constipation, and neurological disease, and diseases associated with the metabolic syndrome have been significantly associated with $\mathrm{OAB}$, even after adjusting for significant confounders, such as age, sex, and nationality.

OAB adversely affects the quality of life of those with the condition and is associated with embarrassment, low self-esteem, and a reduction in economic productivity. In older people, it is associated with of falls, fractures, dermatitis, urinary tract infection, and institutionalization versus those without the condition, even when controlled for the presence of other comorbidities. ${ }^{6-9}$

Guidelines recommend that the first-line treatment for OAB should consist of lifestyle and behavioral measures, such as advice on fluid balance, bladder retraining, 
and urgency suppression techniques. ${ }^{10}$ Some of the lifestyle interventions recommended by the National Institute for Health and Clinical Care Excellence Guidelines from England and Wales include a trial of caffeine reduction, lowering of fluid intake as well as weight loss in females with a body mass index over 30 . Also recommended are behavioral therapies, such as bladder training, for a trial period of 6 weeks. ${ }^{11,12}$ Many of these lifestyle and behavioral techniques require that patients are able to learn, making these measures an impractical option for those with cognitive impairment. ${ }^{13}$ Should these techniques fail or result in a suboptimal level of control then pharmacological therapy is recommended. The current mainstay of pharmacological therapy is treatment with antimuscarinic drugs; these are effective in controlling the symptoms of $\mathrm{OAB}$ and improving health-related quality of life. ${ }^{14}$ More recently, the introduction of mirabegron, a beta-3 agonist, into clinical practice has widened the options for pharmacological management. ${ }^{15}$

Multicomponent therapy including the combination of an $\mathrm{OAB}$ drug with bladder training should be considered if there is no satisfactory benefit from bladder training programs alone. Some of the recommended first-line generic pharmacological agents are oxybutynin (except in frail older persons), tolterodine, or darifenacin (once-daily preparation); other newer branded agents are available. The European Association of Urology acknowledges in its guideline that, although the clinical utility of antimuscarinic drugs has been clearly shown, none of the commonly used antimuscarinics is ideal for all patients. ${ }^{10}$ To achieve best results, treatment should take into account the patient's comorbidities and concomitant medications and the pharmacological properties of each drug. ${ }^{16,17}$ Should drug therapy be warranted, its efficacy obviously depends on a patient taking the prescribed medication and evidence suggests that outcomes are improved when this is so.

\section{Compliance, persistence, and adherence and OAB}

Failure to recognize poor adherence by health care providers may lead to inappropriate increases in medication dose, switches between medications, invasive investigations and more invasive treatment, and an increased cost of disease management. ${ }^{17}$ Many studies in this area use terms, such as compliance, adherence, and persistence, sometimes interchangeably. Medication compliance and medication persistence are different constructs. Medication compliance (synonym: adherence) refers to the degree which the patient conforms to the recommendations about day-to-day treatment directed by the provider with respect to medication timing, dose, and frequency. ${ }^{18}$ Compliance is nowadays a somewhat unfashionable term, thought to reflect outmoded paternalistic medical practice, with the patient doing as he or she is told. The now more usual term, adherence is defined as "the extent to which the patients' behaviour coincides with medical or health advice." ${ }^{18,19}$ This term is preferred by many health care providers because "compliance" suggests that patients passively follow the doctor's orders and that the treatment plan is not based on an agreed contract between provider and recipient. Regardless, the full benefit of the medications that are available will be achieved only if patients follow prescribed treatment regimens. Medication persistence refers to taking the treatment for the prescribed duration, defined as the duration of time from starting to discontinuation of therapy. ${ }^{20}$

\section{Persistence with pharmacological treatment for OAB}

$\mathrm{OAB}$ usually requires long-term treatment to achieve control of symptoms. ${ }^{21}$ Adherence to prescribed drug therapy is therefore important in achieving the best treatment outcomes. However, persistence with long-term medication in many chronic diseases is typically low, ${ }^{22-24}$ but that seen with antimuscarinic drug treatments in OAB appears to be especially poor. ${ }^{25,26}$ For example, in a systematic review of medical claims studies, rates of discontinuation from antimuscarinics used in $\mathrm{OAB}$ ranged from $43 \%$ to $83 \%$ within the first 30 days. ${ }^{26} \mathrm{~A}$ Canadian retrospective study of prescription data in patients with $\mathrm{OAB}$ aged 65 years and above found that the withdrawal rate from two widely used antimuscarinics was in excess of $86 \%$ after 2 years. ${ }^{27}$ In a retrospective study of UK prescription data, $65 \%-86 \%$ of patients discontinued their initial antimuscarinic treatment after 12 months; there was some indication that patients 60 years of age and older might be more likely to persist with prescribed therapy than those aged 40-59 years, but data were inconsistent and overall persistence rates in older people were still relatively low. ${ }^{28}$ A Canadian retrospective study reported on 4-year treatment persistence rates and prescribing pattern of a range of antimuscarinic drugs in OAB and aimed to examine if there were differences in persistence rates with sex, age group, or the choice of the first-line antimuscarinic agent. ${ }^{29}$ Discontinuation rates were similar between males and females but were higher when oxybutynin was used as the first-line (90.8\%) compared with $85.2 \%$ using another antimuscarinic as first-line therapy. 
Withdrawal rates of $65 \%-86 \%$ were reported in the retrospective analysis of UK prescription data for darifenacin, flavoxate, oxybutynin immediate-release (IR)/extendedrelease (ER), propiverine, solifenacin, tolterodine IR/ER, and trospium. ${ }^{28}$ Similar results were also found in Canadian patients with $\mathrm{OAB}$ aged $\geq 66$ years, in which the 2-year withdrawal rates from oxybutynin $(\mathrm{n}=31,996)$ and tolterodine $(n=24,855)$ were $91 \%$ and $86 \%$, respectively. ${ }^{29,30}$ This study did not find any difference in the persistence rates between males and females but did not find an age-related improvement in treatment persistence; though older patients were, in general, no more likely to discontinue their treatment than younger patients.

One other potential cause of the high discontinuation rates in the 4-year study could be that the majority of patients $(87.5 \%)$ received only one drug and were not considered for a second, suggesting that many patients may be suboptimally treated. In a US study on persistence rates in Medicaid patients with $\mathrm{OAB}$, patients were prescribed one of three drugs: once-daily tolterodine ER, oxybutynin chloride ER, and three times-daily oxybutynin IR. Only $32 \%$ of those taking oxybutynin IR and $44 \%$ of those taking either once-daily drug remained adherent for longer than 30 days. Of those remaining after that time, the risk of nonadherence was higher for oxybutynin ER than for tolterodine ER. It was concluded that although persistence was better for those taking once-daily antimuscarinics, there was still a need for a better understanding of nonpersistent patients. ${ }^{31}$ A Canadian study compared persistence rates in 19,485 patients with OAB either on mirabegron or other antimuscarinic agents. In experienced patients, the median number of days on mirabegron was 299 days, compared with a range of 96 to 242 days for the different antimuscarinics; for naïve patients, it was 196 versus 70 to 100 days, respectively. Persistence at 12 months was for mirabegron $39 \%$ versus $14 \%$ to $35 \%$ for antimuscarinics (experienced) and $30 \%$ mirabegron versus $14 \%$ to $21 \%$ antimuscarinics (naïve). Patients who received mirabegron remained longer on treatment than those treated with antimuscarinics and had higher 12-month persistence and adherence rates. This increased persistence may be due to the relative absence of anticholinergic adverse events, which leads to cessation with antimuscarinics. ${ }^{32}$

For drug therapy to be beneficial in chronic conditions, such as $\mathrm{OAB}$, medication titration to achieve maximal adherence and persistence is essential. ${ }^{33,34}$ Patients with poor adherence have increased rates of morbidity, and poor adherence is associated with increased health care resource use and costs. ${ }^{35,36}$ This highlights the importance of recognizing the reasons for the low persistence rates among patients. In a US survey-based study of 5,392 patients examining reasons for nonadherence, it was concluded that treatment efficacy and side effects were the most important factors when considering the discontinuation of $\mathrm{OAB}$ medications in most patients. Most (89\%) reported discontinuing OAB medication due to unmet expectations of the prescribed treatment (46\%) and/or tolerability (21\%); many patients who could not tolerate initial therapy switched to a new antimuscarinic agent (25\%). A smaller group (11\%) indicated that they did not want to take medication. ${ }^{37}$

\section{Long-term conditions and medication taking}

As noted earlier, persistence with long-term medication in many chronic medical conditions is typically low. Cultural beliefs about medication taking, access to health care, and educational and language barriers may also contribute to the low adherence in ethnic minorities. Children and young adults, for example, might be more compliant with treatment if parents supervise their medication. ${ }^{38}$ Variations in drug metabolism, fewer coexistent diseases, and fewer prescribed medicines may also contribute to fewer or better tolerance of side effects and better adherence to therapy in younger people, ${ }^{39}$ except that this has not been consistently observed in OAB treatment studies. ${ }^{28}$ Predictors of better persistence with medication in a Medicaid population included being White, having a previous hospitalization, and prior use of topical drugs or antipsychotics. Factors associated with poor adherence included a previous history of depression and urinary tract infection and an increased number of preexisting medications to be taken. ${ }^{25}$ Drug adherence in chronic illness has been the subject of considerable research over time. Adherence is a crucial step in treatment success and remains a major challenge to achieving this.

A cross-sectional, pilot study assessing adherence in Lebanese adults which sought to identify some of the predictors of poor adherence reported that the clinician-patient relationship, patient forgetfulness, and drug-related adverse effects were associated with medication nonadherence. In this study, half of patients believed that cost of medication might prove a barrier to adherence; the results showed otherwise; neither the cost of medication nor possession of medical insurance predicted the adherence. ${ }^{40}$ This finding is consistent with results from other reports where relative to other criteria, cost is not a major factor in nonadherence. ${ }^{39}$ A quality physician-patient relationship and individualized 
counseling by the physician does have a significant effect in increasing adherence in patients with chronic medical conditions. This is in agreement with much recent evidence suggesting that counseling is the cornerstone in achieving decent levels of adherence. ${ }^{41,42}$ It is crucial that the physician takes the preference of patients seriously when prescribing new medications and involves the patient in decision making around planned treatment. This is especially important in older patients with multiple diseases and resulting polypharmacy. ${ }^{41,43,44}$ Physician counseling has a direct effect on patients' health care literacy and reduces the risk of nonadherence by half. ${ }^{42}$

Cognitive impairment is one of the four major predictors of adherence; for some older patients, declining cognition plays a major role in their medication usage. ${ }^{45}$ These patients are more likely to forget to take drugs and also to forget their physician's instructions. Unfortunately, even proper counseling will have only a transient effect because little, if any, information will be retained by the patient beyond the doctor's office. Additional steps, such as clearly written instructions, may need to be provided in order to improve adherence in this group of patients.

\section{Improving persistence to OAB drugs}

Outside the area of $\mathrm{OAB}$, reducing drug costs, decreasing the frequency of administration, ${ }^{43,46,47}$ use of fixed-dose drug combinations, ${ }^{48}$ and use of generic drugs were found to improve adherence levels. ${ }^{49,50}$ Several aids can help when impaired cognition is a contributor to low adherence in older persons. The use of clear labels and reminders are helpful techniques to address this problem. Simplifying the drug regimen wherever possible may be of use. Overall, once-daily medications rather than three- or four times-daily drugs are better adhered to as most patients find this dosage frequency is more convenient and fits better with daily activities. ${ }^{47}$ Blister packed medications are helpful in helping patients to remember to take their medication in the correct dosages and at the right times. An extensive literature search comparing either pill boxes or blister packing interventions to increase medication adherence showed mean adherence for blister pack subjects of $71 \%$ compared to $63 \%$ with pill boxes. The interventions were most effective when the blister packs were delivered by pharmacies, while interventions were less effective when studies included older or cognitively impaired older persons. ${ }^{51}$

Clinicians should also work on simplifying the patient's drug regimen by removing any unnecessary medication, either that without an indication or where the likelihood of benefit is doubtful. The number of pills and daily dosing frequency can be reduced by the use of fixed-dose combinations although these may be best employed only when stable dosing is achieved. ${ }^{43}$ A recent meta-analysis concluded that the use of fixed-dose combinations was associated with a $26 \%$ reduction in the risk of nonadherence. ${ }^{48}$

Although antimuscarinics have repeatedly been shown to be efficacious and well-tolerated treatments for OAB that also improve health-related quality of life, many patients discontinue therapy prematurely, sometimes before the full therapeutic effects have been established. Having recognized low persistence rates as an ongoing issue in the older patients, what steps might be taken to improve this? A UK study, sponsored by the pharmaceutical industry, demonstrated the success of utilizing an OAB patient support program (the Vesicare Information Programme) to improve persistence with solifenacin therapy by providing patients with educational materials about the nature of OAB, advice about the importance of taking medication as prescribed, and regular telephone follow-up by specialist nurses. Persistence with solifenacin (Vesicare) therapy in these patients was $83 \%$ and $78 \%$ at 3 and 12 months, respectively, after enrollment in the patient support program. Overall, $91 \%$ of patients who responded to the survey found enrollment in the support program helpful, and noted that the progress monitor $(85 \%)$, educational DVD (82\%), and alert card (81\%) were particularly useful. Unfortunately, there was no control group with which to compare usual adherence and no intention to treat analysis. A similar program "YourWay" was established by Pfizer for patients with OAB in the US. Of the 500 patients completing the study of this program, $10.4 \%$ filled a prescription for a $\geq 90$-day supply of fesoterodine. Of those filling a prescription, $26.2 \%$ filled $\geq 1$ prescription and among these, $61.0 \%$ refilled their prescription at least once. Patients filling a prescription were more likely to take fesoterodine as directed. Most patients reported that they were satisfied with various aspects of the plan and their clinicians also reported positive experiences. ${ }^{52}$

Evidence suggests that the addition of focused written behavioral-intervention information to antimuscarinic drug treatment might add to the improvement in OAB symptoms and increase treatment satisfaction in patients who are dissatisfied with their OAB treatment. ${ }^{53}$ However, a recent study from Korea suggested that an educational program failed to enhance persistence with fesoterodine therapy, although two-thirds of the 682 randomized patients failed to complete the study. ${ }^{54}$

Given that most respondents $(89 \%)$ reported discontinuing OAB medication due to unmet treatment expectations (46\%) and side effects $(21 \%),{ }^{37}$ clinicians should provide such 
patients with information which addresses realistic outcomes from drug treatment in addition to that covering lifestyle modifications, urgency suppression, and pelvic floor muscle training. ${ }^{55}$ Clinicians might be able to improve adherence by promoting realistic expectations about treatment and its side effects. Where patients experience unwanted side effects, newer ER formulations should be considered as the use of these is associated with fewer adverse events and improved tolerability. ${ }^{56,57}$ Although the effect of dose titration on adherence and persistence has not been examined in long-term studies, this might be a useful method for optimizing dosing and improving persistence.

For those who do not like taking medication, nonoral routes of drug administration might be considered, but other nonpharmacological options, such as posterior tibial nerve stimulation in addition to fluid and diet modification, bladder training, and urgency suppression techniques, might be viable options to improve symptom control. Of the other treatment modalities, including electrical stimulation, posterior tibial nerve stimulation, sacral neuromodulation, and the intradetrusor injection of botulinum toxin type A, only sacral neuromodulation has been fully endorsed by the International Consultation on Incontinence, ${ }^{16}$ but these guidelines are due for revision in 2016. Whereas advances have been made to reduce the invasiveness of second-line treatment options, they continue to be associated with considerable patient burden both in terms of discomfort, pain, and frequent physician visits resulting in patient inconvenience and increased cost.

\section{Summary}

Adherence and persistence to medications are a challenge in patients with $\mathrm{OAB}$. For optimal results, treatment should be patient-centered to address each person's particular needs and expectations. Published evidence supports decreasing frequency of medication administration, encouraging fixed dosing, blister packing, and patient support programs as strategies to improve this. The effect of dose titration on adherence and persistence remains to be addressed in robustly conducted long-term, community-based studies. Careful dose adjustment might be a promising strategy for optimizing dosing and improving persistence.

\section{Disclosure}

The authors report no conflicts of interest pertinent to this work.

\section{References}

1. Haylen BT, de Ridder D, Freeman RM, et al. An International Urogynecological Association (IUGA)/International Continence Society (ICS) joint report on the terminology for female pelvic floor dysfunction. Neurourol Urodyn. 2010;29(1):4-20.
2. Abrams P, Cardozo L, Fall M, et al. The standardisation of terminology in lower urinary tract function: report from the standardisation sub-committee of the International Continence Society. Urology. 2003;61(1): $37-49$.

3. Irwin DE, Milsom I, Hunskaar S, et al. Population-based survey of urinary incontinence, overactive bladder, and other lower urinary tract symptoms in five countries: results of the EPIC study. Eur Urol. 2006; 50(6):1306-1314; discussion 1314-1305.

4. Canada S. Population Projections for Canada, Provinces and Territories: 2009 to 2036. Ottawa: Statistics Canada; 2010.

5. OfNS. Population Ageing in the United Kingdom, its Constituent Countries and the European Union. London: ONS; 2012.

6. Irwin DE, Milsom I, Reilly K, et al. Overactive bladder is associated with erectile dysfunction and reduced sexual quality of life in men. J Sex Med. 2008;5(12):2904-2910.

7. Wagner $\mathrm{TH}, \mathrm{Hu} \mathrm{TW}$, Bentkover J, et al. Health-related consequences of overactive bladder. Am J Manag Care. 2002;8(19 Suppl): S598-S607.

8. Thom DH, Haan MN, Van Den Eeden SK. Medically recognized urinary incontinence and risks of hospitalization, nursing home admission and mortality. Age Ageing. 1997;26(5):367-374.

9. Kirby MG, Wagg A, Cardozo L, et al. Overactive bladder: Is there a link to the metabolic syndrome in men? Neurourol Urodyn. 2010;29(8): $1360-1364$.

10. Lucas MG, Bosch RJ, Burkhard FC, et al. [European Association of Urology guidelines on assessment and nonsurgical management of urinary incontinence]. Actas Urol Esp. 2013;37(4):199-213.

11. Urinary Incontinence in Women: The Management of Urinary Incontinence in Women. London: National Institute for Clinical Excellence; 2013.

12. Jones C, Hill J, Chapple C; Guideline Development Group. Management of lower urinary tract symptoms in men: summary of NICE guidance. BMJ. 2010;340:c2354.

13. Wagg A, Verdejo C, Molander U. Review of cognitive impairment with antimuscarinic agents in elderly patients with overactive bladder. Int J Clin Pract. 2010;64(9):1279-1286.

14. Chapple CR, Khullar V, Gabriel Z, Muston D, Bitoun CE, Weinstein D. The effects of antimuscarinic treatments in overactive bladder: an update of a systematic review and meta-analysis. Eur Urol. 2008;54(3): $543-562$.

15. Chapple CR, Cardozo L, Nitti VW, Siddiqui E, Michel MC. Mirabegron in overactive bladder: A review of efficacy, safety, and tolerability. Neurourol Urodyn. 2014;33(1):17-30.

16. Abrams P, Andersson KE, Birder L, et al. Fourth International Consultation on Incontinence Recommendations of the International Scientific Committee: Evaluation and treatment of urinary incontinence, pelvic organ prolapse, and fecal incontinence. Neurourol Urodyn. 2010; 29(1):213-240.

17. Abrams P, Larsson G, Chapple C, Wein AJ. Factors involved in the success of antimuscarinic treatment. BJU Int. 1999;83(2 Suppl):42-47.

18. Cramer JA, Roy A, Burrell A, et al. Medication compliance and persistence: terminology and definitions. Value Health. 2008;11(1):44-47.

19. Haynes RB, McKibbon KA, Kanani R. Systematic review of randomised trials of interventions to assist patients to follow prescriptions for medications. Lancet. 1996;348(9024):383-386.

20. Osterberg L, Blaschke T. Adherence to medication. NEngl J Med. 2005; 53:487-497.

21. Abrams P, Kelleher CJ, Kerr LA, Rogers RG. Overactive bladder significantly affects quality of life. Am J Manag Care. 2000;6(11 Suppl): S580-S590.

22. Andrade SE, Walker AM, Gottlieb LK, et al. Discontinuation of antihyperlipidemic drugs - do rates reported in clinical trials reflect rates in primary care settings? N Engl J Med. 1995;332(17):1125-1131.

23. Monane M, Bohn RL, Gurwitz JH, Glynn RJ, Avorn J. Noncompliance with congestive heart failure therapy in the elderly. Arch Intern Med. 1994;154(4):433-437.

24. Partridge AH, Wang PS, Winer EP, Avorn J. Nonadherence to adjuvant tamoxifen therapy in women with primary breast cancer. J Clin Oncol. 2003;21(4):602-606. 
25. Yu YF, Nichol MB, Yu AP, Ahn J. Persistence and adherence of medications for chronic overactive bladder/urinary incontinence in the California Medicaid program. Value Health. 2005;8(4):495-505.

26. Sexton CC, Notte SM, Maroulis C, et al. Persistence and adherence in the treatment of overactive bladder syndrome with anticholinergic therapy: a systematic review of the literature. Int J Clin Pract. 2011; 65(5):567-585.

27. Gomes T, Juurlink DN, Mamdani MM. Comparative adherence to oxybutynin or tolterodine among older patients. Eur J Clin Pharmacol. 2012;68(1):97-99.

28. Wagg A, Compion G, Fahey A, Siddiqui E. Persistence with prescribed antimuscarinic therapy for overactive bladder: a UK experience. BJU Int. 2012;110(11):1767-1774.

29. Wagg A, Diles D. Four year persistence and drug treatment patterns in overactive bladder: data from Canadian datasets. Paper presented at: 68th Annual Meeting of the Canadian Urological Association; 2013; Niagara Falls, ON.

30. Wagg A, Diles D, Berner T. Treatment patterns for patients on overactive bladder therapy: A retrospective statistical analysis using Canadian claims data. JHEOR. 2015;3:43-45.

31. Shaya FT, Blume S, Gu A, Zyczynski T, Jumadilova Z. Persistence with overactive bladder pharmacotherapy in a Medicaid population. Am J Manag Care. 2005;11(4 Suppl):S121-S129.

32. Wagg A, Franks B, Ramos B, Berner T. Persistence and adherence with the new beta-3 receptor agonist, mirabegron, versus antimuscarinics in overactive bladder: Early experience in Canada. Can Urol Assoc J. 2015;9(9-10):343-350.

33. D’Souza AO, Smith MJ, Miller LA, Doyle J, Ariely R. Persistence, adherence, and switch rates among extended-release and immediaterelease overactive bladder medications in a regional managed care plan. J Manag Care Pharm. 2008;14(3):291-301.

34. Benner JS, Becker R, Fanning K, Jumadilova Z, Bavendam T, Brubaker L; OAB Medication Use Study Steering Committee. Bother related to bladder control and health care seeking behavior in adults in the United States. J Urol. 2009;181(6):2591-2598.

35. Krueger KP, Berger BA, Felkey B. Medication adherence and persistence: a comprehensive review. Adv Ther. 2005;22(4):313-356.

36. Schabert VF, Bavendam T, Goldberg EL, Trocio JN, Brubaker L. Challenges for managing overactive bladder and guidance for patient support. Am J Manag Care. 2009;15(4 Suppl):S118-S122.

37. Benner JS, Nichol MB, Rovner ES, et al. Patient-reported reasons for discontinuing overactive bladder medication. BJU Int. 2010;105(9): 1276-1282.

38. Hjalmas K, Hellstrom A, Mogren K, Läckgren G, Stenberg A. The overactive bladder in children: a potential future indication for tolterodine. BJU Int. 2001;87:569-574.

39. Rolnick SJ, Pawloski PA, Hedblom BD, Asche SE, Bruzek RJ. Patient characteristics associated with medication adherence. Clin Med Res. 2013;11(2):54-65.

40. Al-Hajje A, Awada S, Rachidi S. Factors affecting medication adherence in Lebanese patients with chronic diseases. Pharm Pract. 2015; 3(3):590.

41. Gold DT, McClung B. Approaches to patient education: emphasizing the long-term value of compliance and persistence. Am J Med. 2006;119(4 Suppl 1):S32-S37.

\section{Clinical Interventions in Aging}

\section{Publish your work in this journal}

Clinical Interventions in Aging is an international, peer-reviewed journal focusing on evidence-based reports on the value or lack thereof of treatments intended to prevent or delay the onset of maladaptive correlates of aging in human beings. This journal is indexed on PubMed Central, MedLine,
42. Balkrishnan R, Bhosle MJ, Camacho FT, Anderson RT. Predictors of medication adherence and associated health care costs in an older population with overactive bladder syndrome: a longitudinal cohort study. J Urol. 2006;175(3 Pt 1):1067-1071; discussion 1071-1072.

43. Laufs U, Rettig-Ewen V, Böhm M. Strategies to improve medication adherence. Eur Heart J. 2011;32(3):264-268.

44. Moore T, Neher JO, Safranek S. FPIN's clinical inquiries: improving medication adherence in patients with comorbidities. Am Fam Physician. 2011;84(7):1-2.

45. Haynes RB, Ackloo E, Sahota N, McDonald HP, Yao X. Interventions for enhancing medication adherence. Cochrane Database Syst Rev. 2008;(2):CD000011.

46. Claxton AJ, Cramer J, Pierce C. A systematic review of the associations between dose regimens and medication compliance. Clin Ther. 2001;23(8):1296-1310.

47. Coleman CI, Limone B, Sobieraj DM, et al. Dosing frequency and medication adherence in chronic disease. J Manag Care Pharm. 2012; 18(7):527-539.

48. Bangalore S, Kamalakkannan G, Parkar S, Messerli FH. Fixed-dose combinations improve medication compliance: A meta-analysis. Am J Med. 2007;120(8):713-719.

49. Shrank WH, Hoang T, Ettner SL, et al. The implications of choice: Prescribing generic or preferred pharmaceuticals improves medication adherence for chronic conditions. Arch Intern Med. 2006;66(3): 332-337.

50. Briesacher BA, Andrade SE, Fouayzi H, Chan KA. Medication adherence and the use of generic drug therapies. Am J Manag Care. 2009; 15(7):450-456.

51. Conn VS, Ruppar TM, Chan KC, Dunbar-Jacob J, Pepper GA, De Geest S. Packaging interventions to increase medication adherence: systematic review and meta-analysis. Curr Med Res Opin. 2015;31(1):145-160.

52. Trocio JN, Brubaker L, Schabert VF, et al. Fesoterodine prescription fill patterns and evaluation of the YourWay patient support plan for patients with overactive bladder symptoms and physicians. Postgrad Med. 2014;126(3):246-256.

53. Klutke CG, Burgio KL, Wyman JF, et al. Combined effects of behavioral intervention and tolterodine in patients dissatisfied with overactive bladder medication. J Urol. 2009;181(6):2599-2607.

54. Sung HH, Han DH, Kim TH, et al. Interventions do not enhance medication persistence and compliance in patients with overactive bladder: a 24 weeks, randomised, open-label, multi-center trial. Int J Clin Pract. 2015;69(11):1309-1315.

55. Wyman JF, Burgio KL, Newman DK. Practical aspects of lifestyle modifications and behavioural interventions in the treatment of overactive bladder and urgency urinary incontinence. Int J Clin Pract. 2009;63(8):1177-1191.

56. Varadharajan S, Jumadilova Z, Girase P, Ollendorf DA. Economic impact of extended-release tolterodine versus immediate- and extendedrelease oxybutynin among commercially insured persons with overactive bladder. Am J Manag Care. 2005;11(4 Suppl):S140-S149.

57. Staskin DR, Te AE. Short- and long-term efficacy of solifenacin treatment in patients with symptoms of mixed urinary incontinence. $B J U$ Int. 2006;97(6):1256-1261.
Dovepress

CAS, Scopus and the Elsevier Bibliographic databases. The manuscript management system is completely online and includes a very quick and fair peer-review system, which is all easy to use. Visit http://www.dovepress. com/testimonials.php to read real quotes from published authors. 